\title{
Wdrożenie urządzenia QuickCheck firmy PTW do codziennej kontroli stabilności wydajności akceleratorów medycznych
}

\section{Implementation of the PTW QuickCheck in everyday output stability control of medical accelerators}

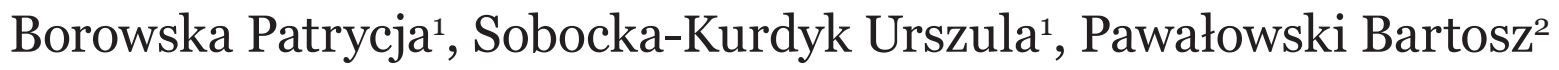 \\ ${ }^{1}$ Zakład Radioterapii III, Wielkopolskie Centrum Onkologii ul. Kaszubska 12 62-8oo Kalisz, Polska \\ ${ }^{2}$ Zakład Fizyki Medycznej, Wielkopolskie Centrum Onkologii ul. Garbary 15 61-866 Poznań, Polska
}

\section{Streszczenie}

Codzienna weryfikacja stabilności pracyakceleratora medycznego poprzez pomiar dawkijest podstawowym testem zapewniającym kontrolę jakości pracy aparatu podczas realizacji leczenia radioterapeutycznego. Celem pracy było wdrożenie oraz zweryfikowanie możliwości zastosowania urządzenia QuickCheck (QCh) firmy PTW Freiburg do codziennej kontroli jakości akceleratorów medycznych. Dokonano porównania dwóch metod pomiarowych wydajności akceleratora, dotychczasowej polegającej na pomiarze z wykorzystaniem komory jonizacyjnej umieszczanej w w fantomie wodnym z urządzeniem QuickCheck. Analiza za pomocą tego urządzenia dostarcza dodatkowych informacji m.in. o charakterystyce wiązki promieniowania jonizującego. Zebrane pomiary za pomocą urządzenia QCh odniesiono do wyników referencyjnych (otrzymanych z pomiarów przeprowadzonych w fantomie wodnym). Na podstawie przeprowadzonej analizy badane urządzenie zostało wdrożone do weryfikacji stabilności wydajności akceleratorów w ramach testów codziennych zgodnych z Rozporządzeniem Ministra Zdrowia w sprawie warunków bezpiecznego stosowania promieniowania jonizującego dla wszystkich rodzajów ekspozycji medycznej. Wyznaczono odpowiednie współczynniki przejścia pozwalające przeliczać uzyskiwane przy pomocy urządzenia QCh wyniki pomiarów na warunki odniesienia w fantomie wodnym.

\footnotetext{
Abstract

Adres do korespondencji

Patrycja Borowska

Zakład Radioterapii III,

Wielkopolskie Centrum Onkologii, ul. Kaszubska 12 62-80o Kalisz

Telefon. +48695189858

e-mail: patrycja.borowska@wco.pl
}

Daily verification of a medical accelerator operation stability by means of dose measurement is a primary quality assurance test in the course of radiation therapy delivery. The aim of this study was to implement and verify the utility of QuickCheck (QCh) device(PTW Freiburg, Germany) in everyday quality assurance 
of medical accelerators. A cross-comparison was made of two methods of accelerator output control: the existing one involving measurement with ionization chamber placed in a water phantom and the QuickCheck test. Analysis with the QCh device provides additional information, including radiation beam characteristics. Measurements collected with QCh and the reference results (obtained with the measurements taken in the water phantom) were collated. Based on the analysis, the QCh device was implemented in the verification of medical accelerators output stability as a part of daily tests performed in accordance with the Polish law on the use of ionizing radiation in medicine. For analysis, appropriate values of transition coefficients were determined to allow to convert test results obtained with the QCh device to the reference conditions in a water phantom.

Stowa kluczowe: stabilność wydajności, codzienna kontrola jakości, QuickCheck, współczynnik przejścia

Keywords: output stability, daily quality assurance, QuickCheck, transition coefficient

\section{Wstęp}

Akcelerator medyczny jest urządzeniem wysokospecjalistycznym wykorzystywanym rutynowo w procesie radioterapii. Jego budowa umożliwia bardzo precyzyjne dostarczanie wysokoenergetycznego promieniowania jonizującego do zmienionych chorobowo narządów pacjenta. Jednym z elementów całego procesu radioterapii jest procedura kontroli jakości aparatów radioterapeutycznych, która zapewnia wysoką jakość realizacji leczenia $[1,2]$. Podczas procesu kontroli jakości wykonuje się testy określone poprzez producenta aparatu [3] ale także wymagane przez Rozporządzeniem Ministra Zdrowia w sprawie warunków bezpiecznego stosowania promieniowania jonizującego dla wszystkich rodzajów ekspozycji medycznej testy eksploatacyjne. Zobowiązują one użytkownika do przestrzegania norm zawartych w rozporządzeniu zgodnie z którymi dla wiązek wysokoenergetycznego promieniowania X i elektronów odchylenie zmierzonej wartości wydajności od wartości odniesienia nie może być większa niż $\pm 3 \%$ [4]. Pomiar wykonywany jest zawsze w dniu pracy aparatu. Weryfikowana jest stabilności wydajności aparatu terapeutycznego. Pomiarów można dokonywać za pomocą komory jonizacyjnej umieszczonej w fantomie stałym lub wodnym [5, 6] oraz za pomocą przeznaczonego do tego celu urządzenia (np. QCh firmy PTW).

Celem niniejszej pracy było wprowadzenie urządzenia QCh do codziennej kontroliwydajnościakceleratorów medycznych, zgodnie z obowiązującymi przepisami prawa [4]. Dodatkowo zbadano stabilność wyznaczonego współczynnika przejścia pozwalającego na przeliczanie wyników pomiarów wykonanych przy użyciu QCh na warunki odniesienia w fantomie wodnym, uwzględniając wpływ efektu narastania dawki na stabilność powyższego współczynnika.

\section{Materiał i metody}

QCh jest urządzeniem przeznaczonym do przeprowadzania testów codziennej kontroli akceleratorów medycznych. Elementem pomiarowym jest 13 komór jonizacyjnych. Zapewnia on pełną automatyzację pomiarów, zarówno dawki, kształtu wiązki jak i parametrów jakości wiązki [7, 8, 9]. Pomiar dawki za pomocą badanego urządzenia uwzględnia różnicę w masie powietrza pomiędzy warunkami referencyjnymi a aktualnymi (korekcja obliczaną dzięki pomiarom temperatury i ciśnienia atmosferycznego przez urządzenie) [7]. Urządzenie umieszczano i pozycjonowano na stole terapeutycznym w osi wiązki (Ryc. 1). Do codziennej kontroli stałości wydajności akceleratorów medycznych wybrano parametr CAX, odpowiadający dawce promieniowania zmierzonej przez centralnie położoną komorę jonizacyjną (Ryc. 2). Dawka ta obliczana jest automatycznie przez urządzenie na podstawie wzoru:

$$
C A X=M_{C A X} \cdot N_{C A X} \cdot k_{T p}
$$




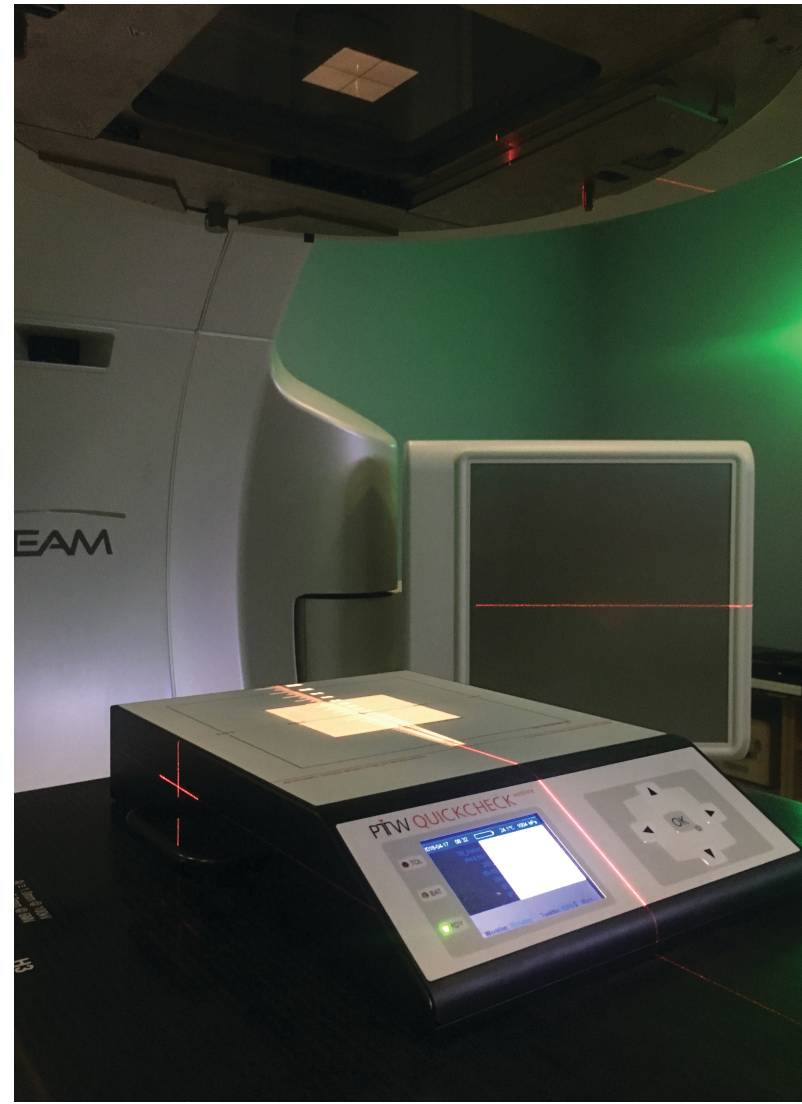

Ryc. 1. Urządzenie QuickCheck ustawione na stole terapeutycznym zgodnie $\mathrm{z}$ instrukcją producenta, przygotowane do rozpoczęcia pomiarów.
CAX - dawka zmierzona przez komorę CAX

$\mathrm{M}_{\mathrm{CAX}}$ - ladunek zmierzony przez komorę CAX

$\mathrm{N}_{\mathrm{CAX}}$ - współczynnik kalibracyjny ${ }^{6 \circ}$ Co komory CAX

$\mathrm{k}_{\mathrm{Tp}}$ - współczynnik korekcji gęstości powietrza

Korekcja gęstości powietrza obliczana jest zgodnie z wzorem:

$$
k_{T p}=\frac{(273.2+T) \cdot p_{0}}{\left(273.2+T_{0}\right) \cdot p}
$$

gdzie:

$\mathrm{T}_{\mathrm{o}}$ - temperatura normalna: $20^{\circ} \mathrm{C}$

$\mathrm{T}-$ zmierzona temperatura $\left[{ }^{\circ} \mathrm{C}\right]$

$\mathrm{p}_{\mathrm{o}}$ - ciśnienie normalne: $1013.25 \mathrm{hPa}$

$\mathrm{p}$ - zmierzone ciśnienie atmosferyczne [hPa]

Jako wartość odniesienia przyjęto pomiary wykonane w fantomie wodnym, przy użyciu komory jonizacyjnej typu Farmer 30013 (PTW Freiburg) i elektrometru UNIDOS (PTW Freiburg). Pomiary wykonywane były zgodnie z zaleceniami zawartymi w raporcie IAEA TRS-398 (International Atomic Energy Agency Technical Report Series-398) (wymiar pola 10cmx10cm i odległość SPD (source phantom distance) - 100cm), czas promieniowania wynosił 200 jednostek monitorowych (JM), moc dawki $600 \mathrm{JM} / \mathrm{min})[5,6]$.

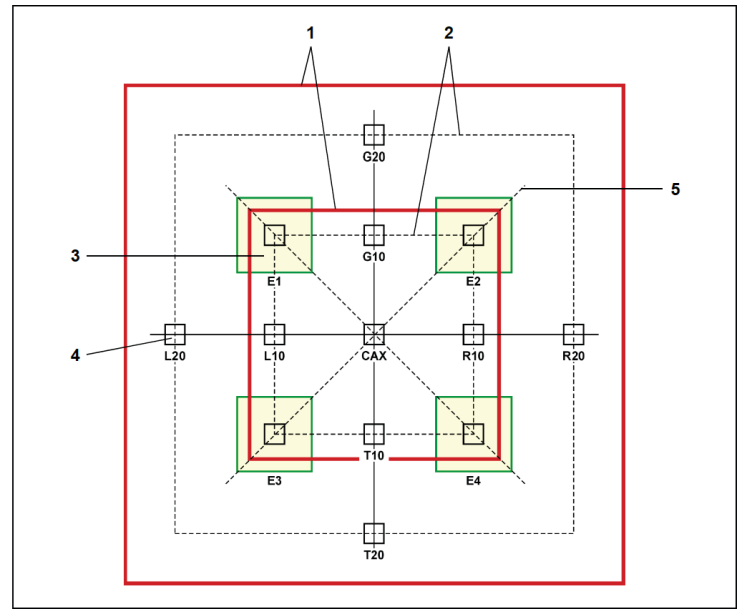

Ryc. 2. Schemat rozmieszczenia komór jonizacyjnych w urządzeniu QuickCheck
Celem porównania pomiarów wyznaczono współczynnik przejścia pomiędzy pomiarem dawki wykonanym QCh, a pomiarem referencyjnym wykonanym w wodzie.

Wydajność akceleratora obliczano, na podstawie pomiarów wykonanych w fantomie wodnym, zgodnie ze wzorem:

$\dot{D}=\frac{D}{M U} \cdot 100$

gdzie:

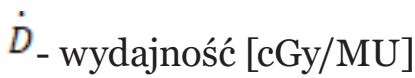

D - dawka zmierzona [Gy], wyznaczona zgodnie z wzorem:

$D_{w, Q}=M_{Q} \cdot N_{D, w, Q_{0}} \cdot k_{Q, Q_{0}}$ 
gdzie:

$\mathrm{D}_{\mathrm{w}, \mathrm{Q}}-$ dawka zmierzona,

$\mathrm{M}_{\mathrm{Q}}$ - odczyt elektrometru, skorygowany ze względu na gęstość powietrza, efekt polaryzacji oraz rekombinacji jonów według wzoru:

$$
M_{Q}={ }_{r a w} M_{Q} \cdot k_{T p} \cdot k_{p o l} \cdot k_{s}
$$

gdzie:

raw $M_{Q}$-surowy odczyt elektrometru,

$\mathrm{k}_{\mathrm{Tp}}$ - współczynnik korekcji gęstości powietrza (obliczany zgodnie z wzorem (2)),

$\mathrm{k}_{\text {pol }}$ - współczynnik korekcji wpływu zmiany polaryzacji przyłożonego napięcia na odpowiedź komory jonizacyjnej,

$\mathrm{k}_{\mathrm{s}}$ - współczynnik korekcji odpowiedzi komory jonizacyjnej ze względu na efekt rekombinacji jonów

$N_{D, w, Q_{0}}$ - współczynnik kalibracyjny zestawu komora jonizacyjna-elektrometr dla referencyjnej jakości promieniowania $\mathrm{Q}_{\mathrm{o}}$ (w przypadku kalibracji ${ }^{6 \circ} \mathrm{Co}$, oznaczany symbolem $\mathrm{N}_{\mathrm{D}, \mathrm{w} \text { ), }}$

$k_{Q, Q_{0}-}$ współczynnik korygujący różnicę odpowiedzi komory jonizacyjnej dla referencyjnej jakości promieniowania $\mathrm{Q}_{0}$ zastosowanej do kalibracji komoryijakości stosowanej przez użytkownika Q (w przypadku kalibracji komory ${ }^{60} \mathrm{Co}$, oznaczany symbolem $\mathrm{k}_{\mathrm{O}}$ ), dla różnych typów komór jonizacyjnych oraz różnych jakości promieniowania Q wartości współczynnika $\mathrm{k}_{\mathrm{Q}}$ zostały wyznaczone i ztabelaryzowane przez Andreo [10], dla jakości niezawartych w tabelach możliwa jest interpolacja wartości współczynnika (zastosowanie obliczonych wartości współczynnika $\mathrm{k}_{\mathrm{Q}}$ prowadzi jednakże do większych niepewności pomiarowych niż jego bezpośrednie wyznaczenie, ponieważ wartości tabelaryczne nie uwzgędniają zmienności współczynnika pomiędzy poszczególnymi egzemplarzami komór jonizacyjnych danego typu [5]).

MU - ilość jednostek monitorowych promieniowania

Wyniki uzyskane na podstawie pomiarów wykonanych urządzeniem QCh, przeliczono na warunki referencyjne, zgodnie ze wzorem:

$$
\dot{D}_{Q C}=\frac{C A X}{M U} \cdot 100 \cdot k_{\text {cross }}
$$

gdzie:

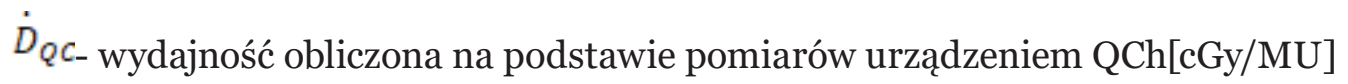

CAX - dawka zmierzona przez centralną komorę jonizacyjną urządzenia QCh, obliczona automatycznie zgodnie z wzorem (1) [Gy]

MU - ilość jednostek monitorowych promieniowania

$\mathrm{k}_{\text {cross }}$ - współczynnik przejścia QCh-woda 
Weryfikacji dokonano zarówno w pomiarach bezpośrednich, jak i z zastosowaniem dodatkowego obszaru narastania dawki w postaci 3cm warstwy PMMA. Analizy stabilności współczynnika przejścia dokonano na podstawie serii siedmiu cotygodniowych pomiarów. urządzeniem QCh.

\section{Wyniki}

Zgodność wyników uzyskanych z pomiarów urządzeniem QuickCheck z wartościami referencyjnymi zbadano testem korelacji liniowej Pearsona. Wykres ilustrujący powyższą zależność dla akceleratora TrueBeam (energia 6MV) zilustrowano na ryc. 3.

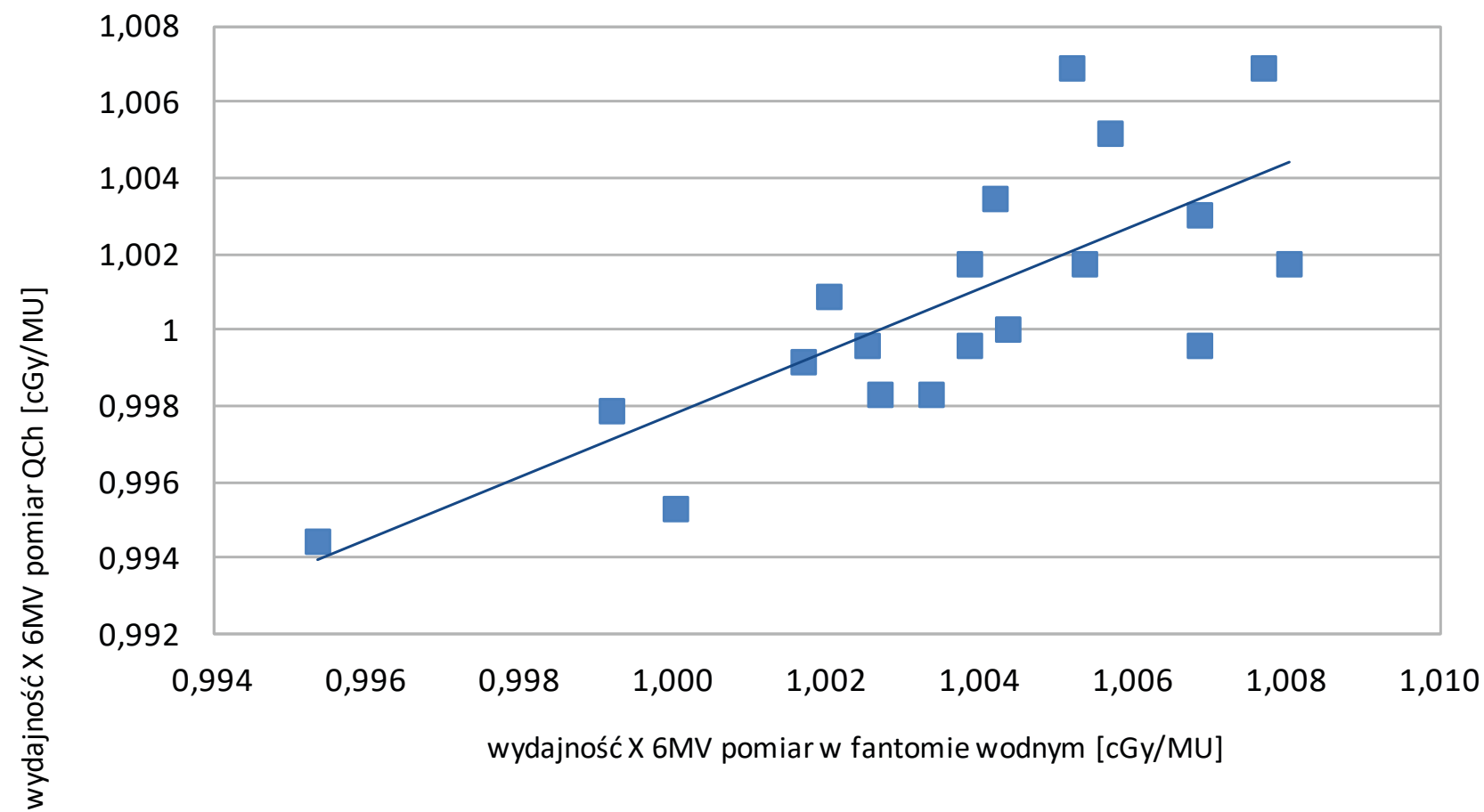

Ryc. 3. Korelacja pomiędzy wartościami wydajności akceleratora wyznaczonymi przy użyciu urządzenia QuickCheck i w fantomie wodnym dla energii X 6MV dla akceleratora TrueBeam.

Dla poszczególnych energii fotonowych uzyskano następujące wartości współczynników korelacji:

Clinac 2300, energia X $6 \mathrm{MV}: \mathbf{r}=\mathbf{0 , 7 6 7 3}$

Clinac 2300, energia X $20 \mathrm{MV}: \mathbf{r}=\mathbf{0 , 7 2 1 4}$

TrueBeam, energia X 6 MV: r = $\mathbf{0 , 7 6 2 3}$

TrueBeam, energia X 15 MV: r = o,7432

Na podstawie obserwacji stwierdzono, że wpływ zmiennych warunków zewnętrznych na wartość współczynnika przejścia QCh-woda jest pomijalny, a wyznaczane wartości nie odbiegają od obliczonej średniej o więcej niż 1\%. Do dalszych obliczeń uśredniono uzyskane, w całym okresie obserwacji, wartości współczynników przejścia dla poszczególnych energii fotonowych.

Wykres (Ryc.4) ilustruje zmienność wydajności akceleratora TrueBeam (6MV) w czasie, wyznaczoną na podstawie pomiarów wykonanych w fantomie wodnym oraz za pomocą urządzenia QCh. 

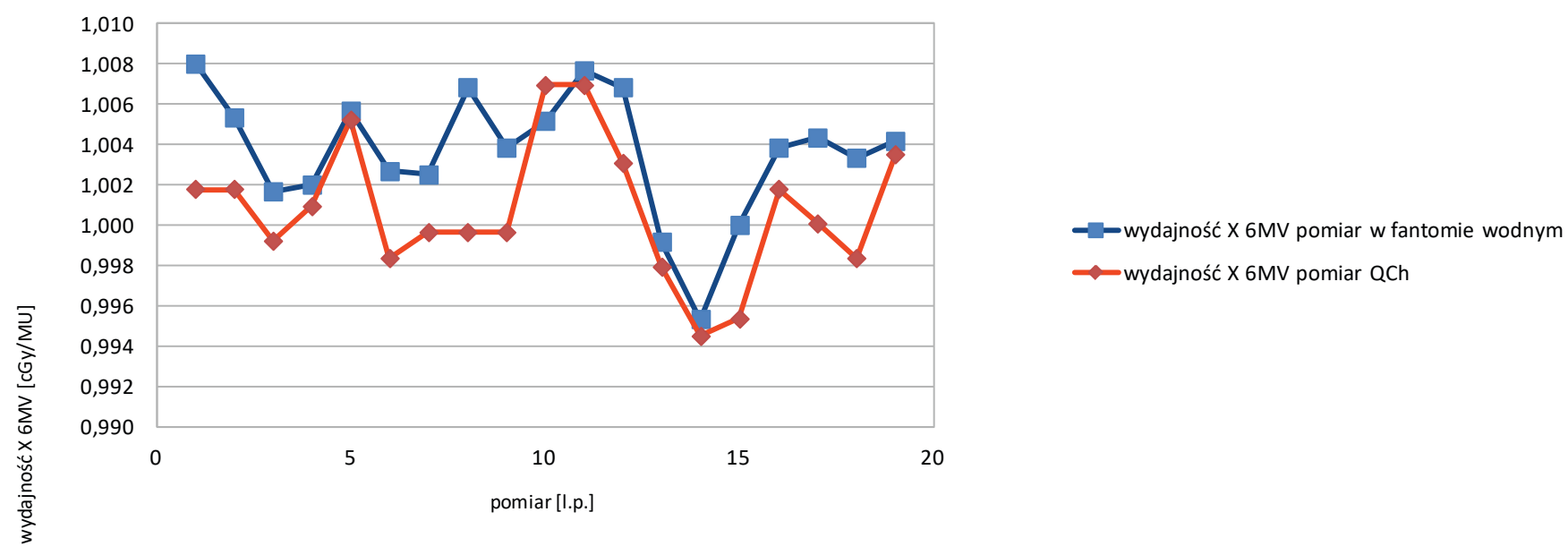

Ryc. 4. Zmienność wydajności akceleratora TrueBeam dla energii X 6MV wykreślona dla pomiarów wykonanych w fantomie wodnym oraz przy użyciu urządzenia QuickCheck

\section{Wnioski}

Wyznaczone testem Pearsona wysokie wartości współczynników korelacji pomiędzy wartościami wydajności akceleratorów medycznych uzyskanymi na podstawie pomiarów w fantomie wodnym i z użyciem urządzenia QuickCheck dowodzą przydatności przyrządu w codziennej kontroli jakości aparatów terapeutycznych.

Użycie uśrednionych wartości współczynników przejścia jest dobrą praktyką, pozwalajacą wyeliminować błędy grube przy wyznaczaniu tychże współczynników, mogące wynikać na przykład z niedokładności ustawienia przyrządu pomiarowego na stole terapeutycznym.

\section{Konflikt interesu/ Conflict of interest}

Nie występuje / None

\section{Finansowanie/ Financial suport}

Nie występuje / None

\section{Etyka/ Ethics}

Treści przedstawione w artykule są zgodne z zasadami Deklaracji Helsińskiej, dyrektywami EU oraz ujednoliconymi wymaganiami dla czasopism biomedycznych.

\section{Piśmiennictwo / References}

[1] Malicki, J, Ślosarek, K., red., Planowanie leczenia i dozymetria w radioterapii, Via Medica, Gdańsk 2016.

[2] Kukułowicz, P., Charakterystyka wiązek terapeutycznych stosowanych w radioterapii, Komitet Fizyki Medycznej, Radiobiologii i Diagnostyki Obrazowej PAN, Polskie Towarzystwo Fizyki Medycznej, Wrocław 2017

[3] TrueBeam Instructions for Use, VARIAN medical systems, 2013

[4] Obwieszczenie Ministra Zdrowia z dn. 3 kwietnia 2017r. w sprawie ogłoszenia jednolitego tekstu rozporządzenia Ministra Zdrowia w sprawie warunków bezpiecznego stosowania promieniowania jonizującego dla wszystkich rodzajów ekspozycji medycznej. Dz. U. 2017 poz. 884 
[5] IAEA. Technical Report Series no. 398, Absorbed Dose Determination in External Beam Radiotherapy: An International Code of Pracice for Dosimetry Based on Standards of Absorbed Dose to Water. Vienna, 2000

[6] Łobodziec, W., Dozymetria promieniowania jonizującego w radioterapii, Wydawnictwo Uniwersytetu Śląskiego, Katowice 1999

[7] User Manual QUICKCHECK System QUICKCHECKwebline T42031. PTW

[8] TrueBeam Stability: Results After 6 Months, URL: https://www.wienkav.at/kav/kfj/91033454/physik/ tb/tb_beam_stability.htm, dostęp z: 19.11.2018 r.

[9] Mosleh-Shirazi Mohammad, Rahimi Saeed, Karbasi Sareh, Medium-Term Stability of the Photon Beam Energy of an Elekta CompactTM Linear Accelerator Based on Daily Measurements of Beam Quality Factor, Iranian Journal of Medical Physics, vol. 12, no. 4, 2015, 230-234

[10] Andreo, P., Absorbed dose beam quality factors for the dosimetry of high-energy photon beams, Physics in Medicine and Biology 37, 1992

\section{Spis rycin i tabel}

- Ryc. 1. Urządzenie QuickCheck ustawione na stole terapeutycznym zgodnie z instrukcją producenta, przygotowane do rozpoczęcia pomiarów.

- Fig. 1. QuickCheck device, positioned in accordance with the user manual, prepared for the measurement

- Ryc. 2. Schemat rozmieszczenia komór jonizacyjnych w urządzeniu QuickCheck [7].

- Fig. 2. Schematic representation of the detector design in the QuickCheck appliance [7].

- Ryc. 3. Korelacja pomiędzy wartościami wydajności akceleratora wyznaczonymi przy użyciu urządzenia QuickCheck i w fantomie wodnym dla energii X 6MV dla akceleratora TrueBeam.

- Fig. 3. Correlation between dose output measurements performed using the Quick Check device and in the water phantom plotted for the True Beam X 6 MV.

- Ryc. 4. Zmienność wydajności akceleratora TrueBeam dla energii X 6MV wykreślona dla pomiarów wykonanych w fantomie wodnym oraz przy użyciu urządzenia QuickCheck

- Fig. 4. Variability of the accelerator output for the TrueBeam X6MV energy plotted for measurements performed in the water phantom as a reference and based on the calculations for the QuickCheck test. 